\title{
PERANCANGAN STREET FURNITURE PADA RUANG TERBUKA PUBLIK KLOJEN KULINER HERITAGE KOTA MALANG
}

\author{
Putri Herlia Pramitasari \\ Dosen Prodi Arsitektur, Fak. Teknik Sipil dan Perencanaan, ITN Malang \\ e-mail: putri herlia@lecturer.itn.ac.id \\ Maria Istiqoma \\ Dosen Bahasa Inggris, Fak. Teknik Sipil dan Perencanaan, ITN Malang \\ e-mail: maria istiqoma@lecturer.itn.ac.id

\section{Sri Winarn} \\ Dosen Prodi Arsitektur, Fak. Teknik Sipil dan Perencanaan, ITN Malang \\ e-mail: sriwinarni@lecturer.itn.ac.id
}

\begin{abstract}
ABSTRAK
Elemen fisik sarana prasarana pejalan kaki memiliki peran yang vital dalam perancangan ruang terbuka publik. Tatanan elemen street furniture pada kondisi eksisting kawasan Klojen Kuliner Heritage belum optimal dari aspek fungsi, tata visual, juga lingkungan dalam pemenuhan kebutuhan dan kenyamanan pengguna pada ruang terbuka publik. Metode perancangan glassbox melalui pendekatan desain yang rasional dijadikan sebagai pendekatan perancangan dalam tahap pengembangan desain elemen fisik pejalan kaki pada objek studi dengan analisis deskriptif. Perancangan elemen penanda berupa gate serta jalur pedestrian menjadi fokus pengembangan desain pada kajian ini. Desain elemen street furniture dirancang berkarakter dan edukatif untuk memperkuat citra dan identitas kawasan.
\end{abstract}

Kata kunci : street furniture, klojen kuliner heritage, ruang publik.

\begin{abstract}
The physical elements of pedestrian infrastructure have a vital role in the design of public open spaces. The element arrangements of street furniture in the existing conditions of Klojen Kuliner Heritage area have not been developed optimally in terms of function, visual structure, and environment to meet the needs and comfort of users in public open spaces. Glassbox design method through a rational design approach was used in the development stage of physical elements of pedestrians on the study object by using descriptive analysis. The design of marker elements in the form of gates and pedestrian pathways was the focus of design development in this study. The design of street furniture elements is formed to be characterized and educative to strengthen the image and identity of the region.
\end{abstract}

Keywords : street furniture, klojen culinary heritage, public spaces. 


\section{PENDAHULUAN}

Identitas kawasan dapat diperkuat dari adanya perancangan street furniture yang baik. Pramitasari, P. H., et al (2020) menyatakan bahwa kondisi eksisting elemen street furniture kawasan Klojen Kuliner Heritage belum optimal mengakomodir kebutuhan serta kenyamanan pengguna dilihat dari aspek fungsi, visual, dan lingkungan.

Permasalahan eksisting yang dijumpai pada kawasan objek studi sepanjang Jl.Trunojoyo, Kelurahan Klojen, Kota Malang, diantaranya jalur pejalan kaki banyak yang mengalami kerusakan akibat dijadikan area parkir kendaraan bermotor, minimnya elemen penanda kawasan Klojen Kuliner Heritage, serta tidak adanya marka khusus kaum diffable atau penyandang cacat. Oleh karena itu, diperlukan tatanan street furniture yang dapat memenuhi kebutuhan, kenyamanan pengguna, serta memperkuat identitas kawasan.

\section{TINJAUAN PUSTAKA}

Ruang terbuka publik kota menurut Shirvani (1985) dalam Rahmiati (2017) adalah semua elemen lansekap, taman, hardscape (jalan, trotoar, dan sebagainya), dan ruang rekreasi pada suatu kota. Sistem ruang terbuka kota dibentuk oleh pengaturan elemen-elemen ruang terbuka kota dalam suatu urutan pengaturan yang saling berkaitan sehingga menciptakan bentuk ruang terbuka yang fungsional.

Fungsi utama ruang terbuka dalam suatu kawasan perkotaan, diantaranya (Rahmiati, 2017):

a. Menjaga ketersediaan lahan sebagai kawasan resapan air.

b. Menciptakan aspek planologis perkotaan melalui keseimbangan antara lingkungan alam dan lingkungan binaan yang berguna untuk kepentingan masyarakat.

c. Meningkatkan keserasian lingkungan perkotaan sebagai sarana pengaman lingkungan perkotaan yang aman, nyaman, segar, indah, dan bersih.

Perancangan desain lansekap perkotaan tidak hanya bersifat universal, seperti nilai-nilai estetika, namun juga nilai-nilai lokal. Adapun kriteria perancangan desain lansekap perkotaan, yaitu (Muerb, 1995 dalam Soemardiono, B., dan Gusma, A. F., 2014):

a. Menjaga estetika ruang dan ecological landscape sebagai elemen utama dalam perancangan lansekap perkotaan dengan tetap 
mempertahankan nilai-nilai historis, serta menghindari pandangan visual yang berbahaya dalam perancangan lansekap kota.

b. Merancang pintu masuk dan elemen penanda (signage) dengan konsep green.

c. Mempertahankan kawasan Ruang Terbuka Hijau (RTH) atau area hijau untuk meminimalisir dampak negatif terhadap lingkungan.

d. Menghindari pengembangan desain dan pembangunan lansekap kota yang berdampak negatif terhadap lingkungan.

Ruang terbuka publik merupakan salah satu bagian dari perkotaan, sehingga dalam setiap perancangan ruang terbuka publik harus memperhatikan elemen pembentuk ruang kota agar dapat memberikan karakteristik yang baik bagi kota tersebut. Adapun elemen pembentuk ruang kota menurut Shirvani (1985) dalam Rahmiati, D. (2017), yaitu tata guna lahan (land use), bentuk dan massa bangunan (building form and massing), sirkulasi dan parkir (circulation and parking), ruang terbuka (open space), jalur pedestrian (pedestrian ways), penanda (signages), kegiatan pendukung (activity support), dan konservasi (conservation).

Penataan elemen street furniture (perabot ruang bagi pejalan kaki) yang berkarakter juga diperlukan untuk meningkatkan identitas kawasan. Penyediaan sarana dan prasarana ruang bagi pejalan kaki pada sisi jalan (sidewalk) maupun pada area Ruang Terbuka Hijau (RTH-green pathway), baik jalur pejalan kaki, jalur hijau, marka untuk penyandang cacat (diffable), lampu penerangan, tempat duduk, tempat sampah, elemen penanda, dan drainase juga perlu dirancang untuk memenuhi kebutuhan dan kenyamanan ruang publik, serta identitas kawasan.

Beberapa faktor yang harus diperhatikan dalam perancangan ruang publik, yaitu kesatuan, proporsi, skala, harmoni, keseimbangan, serta ritme dan kontras pada ruang publik (Anggriani, N. 2010).

Komponen desain lansekap pada perancangan ruang publik, meliputi (Hakim, R., dan Utomo, H. 2008):

a. Prinsip desain; keseimbangan (balance), irama dan pengulangan (rhytm and repetition); garis, bentuk, tekstur, ruang, dan warna, serta penekanan dan aksentuasi (emphasis).

b. Unsur desain; garis, bidang, ruang, bentuk, fungsi, tekstur, dan warna.

Kajian kali ini membahas terkait pengembangan desain elemen street furniture terhadap komponen desain ruang terbuka publik yang berkarakter dan dapat memperkuat identitas Klojen kuliner heritage. 


\section{METODE PENELITIAN}

Metode perancangan glassbox dilakukan pada tahapan pengembangan desain pada kajian ini, dimana metode desain dibuat secara rasional dan logis hingga menghasilkan gambar kerja arsitektural yang logis dan bermakna. Tahapan pengembangan desain yang dilakukan, yaitu pengumpulan data, analisis data, dan interpretasi data. Produk tahapan pengembangan desain, yaitu berupa gambar kerja arsitektural yang dibuat dari pengembangan konsep dan gambar pra-desain objek studi.

Metode pengumpulan data dilakukan melalui pengumpulan data primer berupa observasi lapangan, dan pengumpulan data sekunder berupa kajian objek preseden dan studi literatur. Objek studi dilakukan pada area jalur pedestrian JI. Trunojoyo, Kelurahan Klojen, Kecamatan Klojen, Kota Malang.

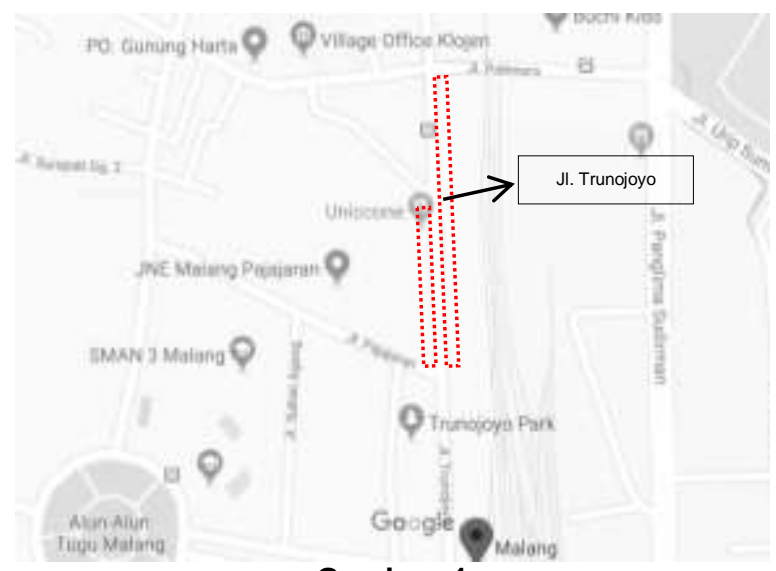

Gambar. 1

Lokasi objek studi.

Sumber: Analisis penulis, 2020

Metode analisis data dilakukan secara deskriptif dari pengembangan desain elemen street furniture, berupa jalur pedestrian dan elemen penanda (signage) terhadap komponen desain lansekap pada ruang publik, baik aspek prinsip dan unsur desain.

\section{HASIL DAN PEMBAHASAN}

Pembahasan desain pengembangan objek studi terkait komponen desain lansekap pada elemen penanda dan jalur pedestrian pada $\mathrm{Jl}$. Trunojoyo, Kota Malang.

\subsection{Elemen Penanda}

Elemen penanda (signage) terletak pada posisi hook pertigaan $\mathrm{Jl}$. Padjajaran dan Jl. Trunojoyo, Malang seperti terlihat pada Gambar 2. 
Elemen penanda didesain sebagai taman hijau sekaligus berfungsi terdapat tempat duduk, papan nama, dan penerangan sebagai elemen dekoratif.

Prinsip desain pada elemen penanda ini menggunakan keseimbangan asimetris dengan irama atau perulangan garis, bidang, dan bentuk lingkaran sebagai bentuk dasar signage, perulangan ornamen atau elemen dekoratif perlengkapan makan atau kuliner, perulangan tekstur halus dan kasar, juga perulangan warna pada bagian tempat duduk, ornamen dekoratif, plat elemen penanda, dan papan nama. Aksentuasi atau penekanan elemen penanda dijadikan sebagai titik pusat perhatian (point of interest) menggunakan konsep desain dinamis dan tema kuliner sehingga desain yang dibuat dioptimalkan dapat memperkuat identitas Klojen kuliner heritage.

Unsur desain yang digunakan pada desain elemen penanda, yaitu:

1. Dominasi garis lengkung untuk memperkuat konsep dinamis, memberi pengaruh gembira, dan menciptakan suasana ruang yang menarik.

2. Dominasi bidang lurus berfungsi sebagai bidang pembatas fisik dengan desain dibuat tidak masif agar tidak mengganggu batasan pandangan visual pengguna.

3. Ruang bersifat sebagai ruang terbuka aktif, dimana dapat dimanfaatkan pula untuk tempat duduk dan berfoto. Ruang terbuka lingkungan ini secara langsung dapat meningkatkan fungsi sosial dan ekologis sebagai ruang terbuka positif.

4. Dominasi bentuk lengkung dimaksudkan untuk memberikan kesan dinamis, bergerak, dan aktif.

5. Elemen penanda berfungsi sebagai ruang terbuka publik.

6. Dominasi tekstur kasar dari jarak pandang dekat sebagai upaya untuk meminimalisir kesan statis dan monoton pada desain.

7. Penggunaan warna netral dan hangat, yaitu hitam, coklat, hijau, dan warna tata cahaya kuning agar kontekstual dengan lingkungan dan memberikan kesan menyenangkan. 

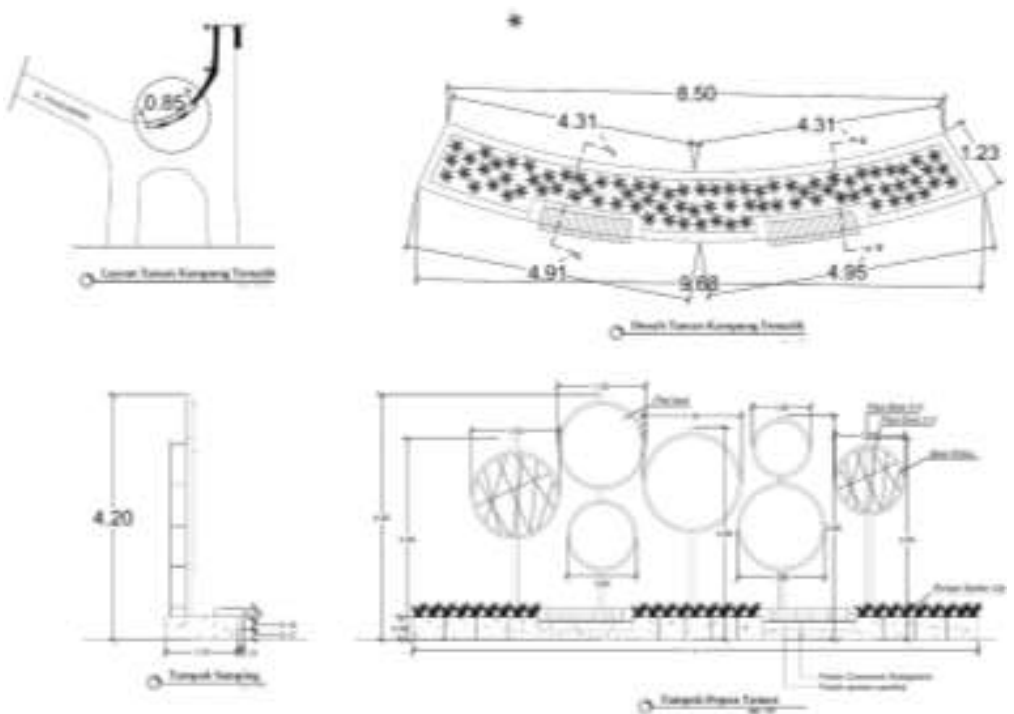

Gambar. 2

Gambar kerja desain signage.

Sumber: Analisis penulis, 2020

Elemen penanda didesain lebih berkarakter untuk memperkuat citra kawasan sebagai area kuliner (Gambar 3). Pemanfaatan material plat besi, decking kayu untuk tempat duduk, dan bata merah dengan finishing kamprot agar kontekstual dengan lingkungan, memudahkan perawatan dan pemeliharaan, dan berkesan modern mengikuti perkembangan zaman. Aksen penerangan buatan berupa lampu LED stripe pada setiap plat besi elemen penanda juga semakin menambah estetika dan daya tarik visual bagi masyarakat. Papan nama bertuliskan "CULINARY HERITAGE" juga diterapkan pada desain agar identitas kawasan semakin kuat. Tanaman bakung juga ditambahkan untuk semakin mempercantik taman dengan pemeliharaan dan perawatan yang mudah. 


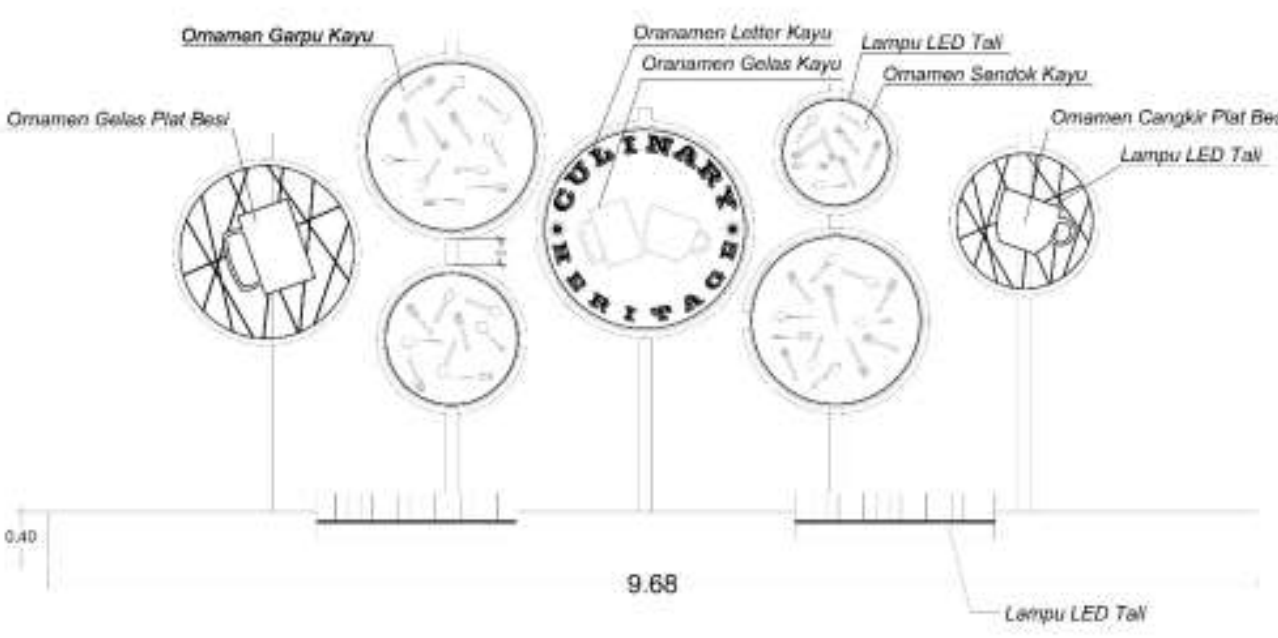

Tampak Depan Lampu Hias

Gambar. 3

Detail signage.

Sumber: Analisis penulis, 2020

Papan nama bertuliskan "KLOJEN" dengan tata cahaya LED berwarna hijau dan material akrilik semakin menghidupkan suasana pada area tersebut sebagaimana dapat dilihat pada Gambar 4. Identitas kawasan pun semakin jelas dengan harapan masyarakat menjadi tergerak untuk memanfaatkan ruang terbuka publik yang telah disediakan sekaligus berperan sebagai media transfer pengetahuan pada masyarakat. Citra dan identitas kawasan pun mulai dikenal masyarakat dan semakin berkembang dengan adanya tambahan elemen penanda ini. 

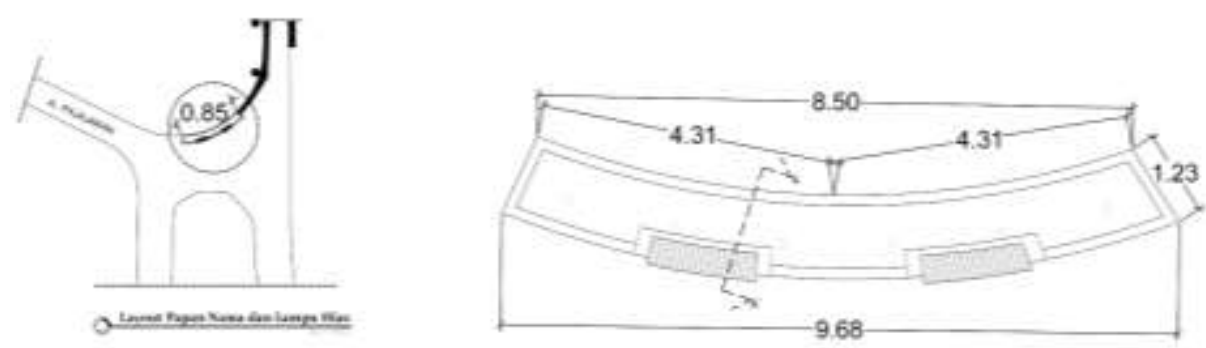

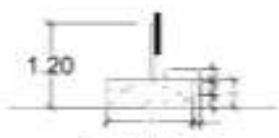

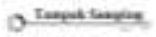

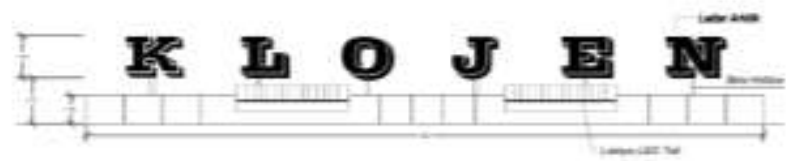

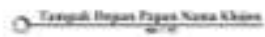

Gambar. 4

Detail letter block signage.

Sumber: Analisis penulis, 2020

\subsection{Jalur Pedestrian}

Prinsip desain pada jalur pejalan kaki menggunakan keseimbangan simetris dengan irama atau perulangan garis, bidang, dan bentuk ornamen lengkung, perpaduan tekstur halus dan kasar dengan adanya marka diffable, serta perulangan warna hijau dan kuning sebagai warna hangat. Aksentuasi atau penekanan bentuk ornamen lengkung menggunakan konsep desain rileks dan dinamis.

Unsur desain pada desain jalur pedestrian, diantaranya:

1. Penggunaan garis horizontal banyak diterapkan untuk menciptakan kesan rileks dan nyaman bagi pengguna.

2. Penggunaan bidang lurus berfungsi sebagai bidang alas/ dasar berupa lantai paving.

3. Jalur pejalan kaki berupa lantai sebagai komponen pembentuk ruang dengan pola sirkulasi linier.

4. Bentuk geometris yang disusun teratur memadukan bentuk persegi dan lengkung untuk memberikan kesan rileks, tenang, namun tetap dinamis.

5. Jalur pedestrian berfungsi sebagai sarana bagi para pejalan kaki pada ruang terbuka publik. 
6. Kombinasi tekstur halus dan tekstur kasar untuk memfasilitasi kebutuhan bagi para pengguna umum dan para penyandang cacat (diffable) sehingga desain lebih fungsional dan estetis.

7. Kombinasi warna dingin sebagai warna dasar melalui penggunaan paving abu-abu dipadukan dengan warna hangat, yaitu ornamen hijau dan kuning agar area pejalan kaki terkesan lebih luas, kontekstual dengan lingkungan, dan dinamis.

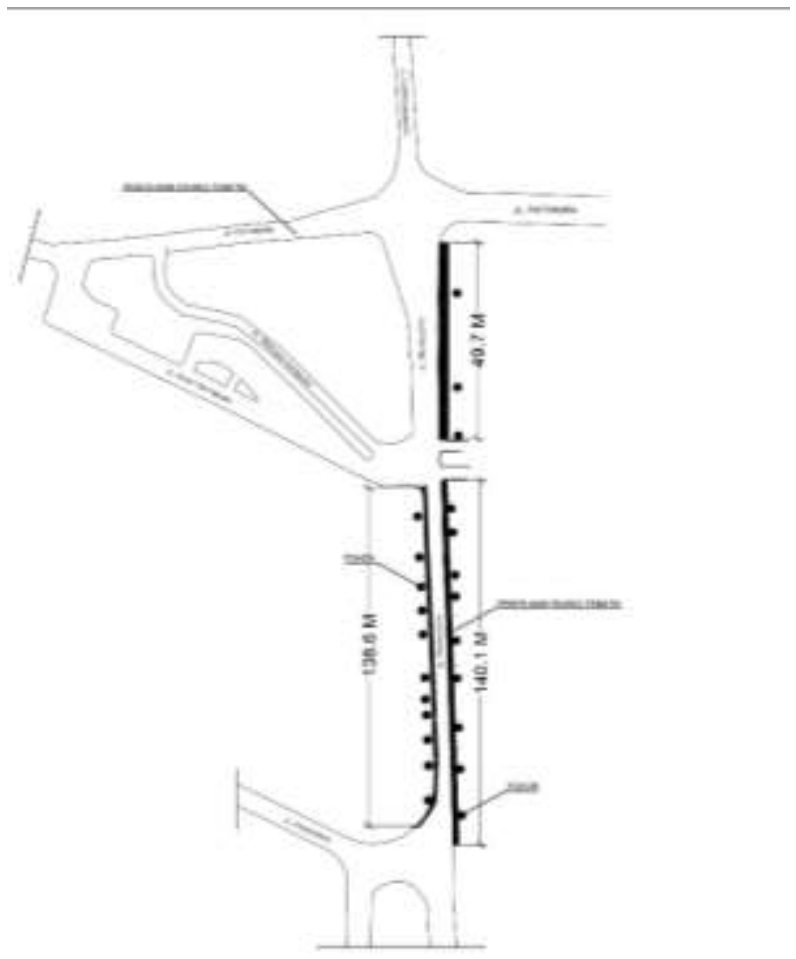

\section{LAY OUT RENCANA IL TRUNOJONO-IL. PATIMURA}

Gambar. 5

Rencana jalur pedestrian.

Sumber: Analisis penulis, 2020

Area lokasi pejalan kaki, yaitu sepanjang Jl. Trunojoyo seperti terlihat pada Gambar 5. Jalur pedestrian mengikuti lokasi eksisting dengan memperbaiki kondisi jalur pedestrian yang rusak diganti dengan desain sesuai Gambar 6. Saluran drainase pada trotoar juga disesuaikan dengan kemiringan tanah. Pemanfaatan material paving juga berfungsi sebagai area resapan air hujan sehingga daya dukung ekosistem lingkungan tetap terjaga dan berkelanjutan. Perbaikan trotoar ini diharapkan diiringi pula dengan perubahan tata laku masyarakat agar area parkir motor tidak lagi pada 
trotoar yang dapat mempercepat kerusakan paving sehingga mengakibatkan ketidaknyamanan bagi pengguna.
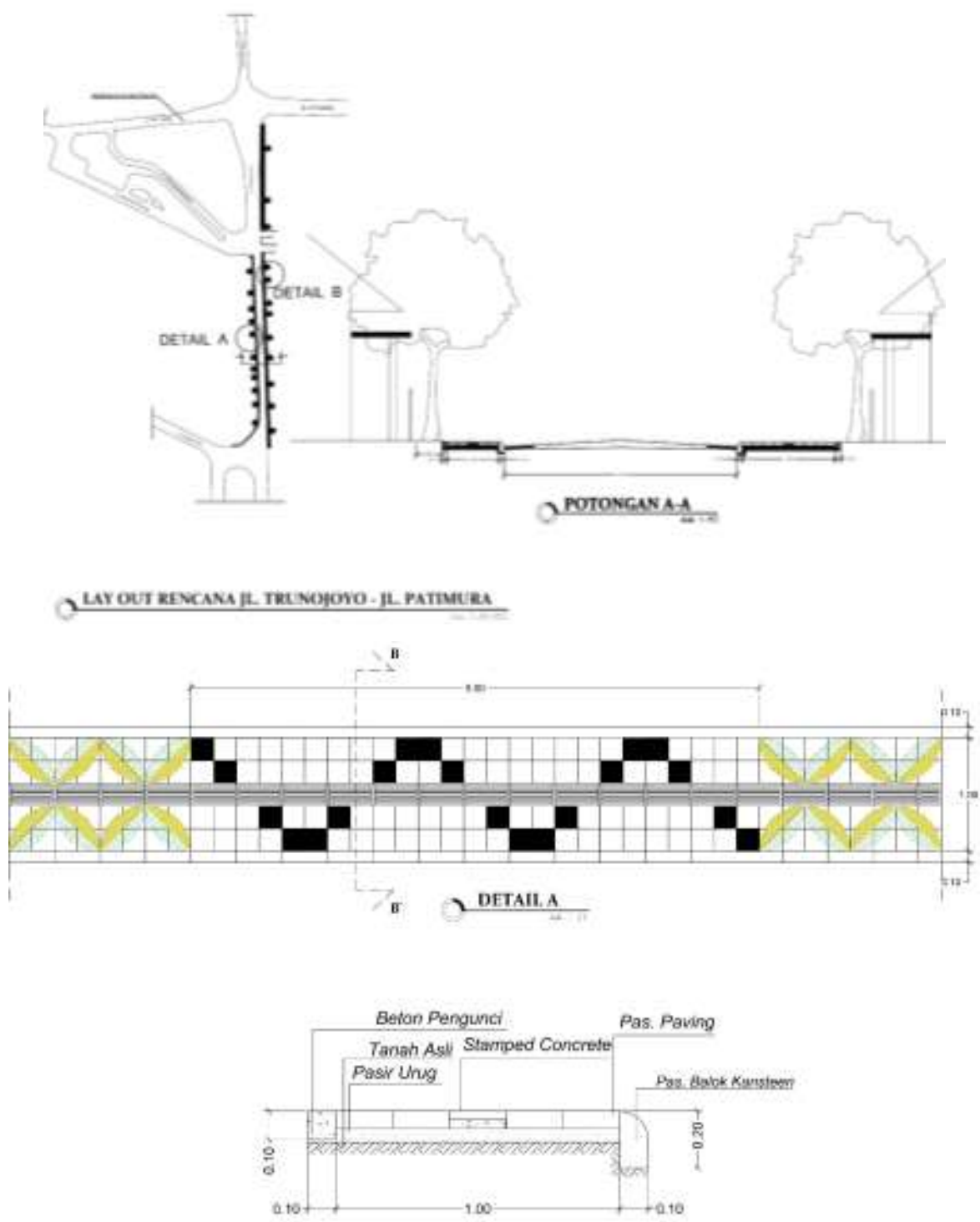

2 POT B-B'

Gambar. 6

Potongan AA' dan BB' pada jalur pedestrian.

Sumber: Analisis penulis, 2020

\section{KESIMPULAN}

Optimasi desain elemen street furniture pada kawasan Klojen kuliner heritage Jl. Trunojoyo, Kota Malang berupa elemen penanda dan jalur 
pejalan kaki dilakukan dengan mempertimbangkan komponen prinsip dan unsur desain lansekap pada ruang terbuka publik. Konsep dinamis diangkat sebagai tema utama perancangan agar tercipta ruang terbuka publik yang aktif dan menyenangkan untuk memenuhi kebutuhan pengguna dan kenyamanan bagi masyarakat. Desain elemen street furniture tersebut dibuat berkarakter dan edukatif agar citra dan identitas semakin kuat pada kawasan objek studi.

Kajian selanjutnya dapat dikembangkan untuk eksplorasi desain elemen sarana pejalan kaki lainnya, seperti tempat sampah, lampu penerangan, jalur hijau, papan informasi, halte, saluran drainase, dan sebagainya pada objek studi.

\section{DAFTAR PUSTAKA}

Anggriani, N. 2010. Ruang Publik dalam Perancangan Kota. Klaten: Yayasan Humaniora.

Hakim, R., dan Utomo, H. 2008. Komponen Perancangan Arsitektur Lansekap - Prinsip - Unsur dan Aplikasi Desain. Jakarta: Bumi Aksara.

Pramitasari, P. H., et al. 2020. Peran Elemen Street Furniture pada Desain Ruang Publik Kawasan Klojen Kuliner Heritage di Kota Malang. Seminar Nasional Infrastruktur Berkelanjutan Era Revolusi Industri 4.0 Fakultas Teknik Sipil dan Perencanaan, ITN Malang, IV, 117-124.

Rahmiati. 2017. Kajian Elemen Pembentuk Ruang Kota pada Ruang Terbuka Publik Kota (Studi Kasus: Alun-Alun Karanganyar). Jurnal IKRAITH-TEKNOLOGI, 1 (2), 1-8.

Soemardiono, B., dan Gusma, A. F. 2014. The Development of Code River Area in Yogyakarta as a Sustainable Urban Landscape Asset Acknowledging Local Traditional Knowledge. International Review for Spatial Planning and Sustainable Development, 2 (4), 4-18. 
